\title{
Measures to improve the comfort of cataract surgery patients: a systematic review and meta-analysis
}

\author{
Kun Zeng ${ }^{1,2}$, Qiang $\mathrm{Li}^{3}$, Wenqun $\mathrm{Xi}^{1,2}$, Yuanjiao Qiao ${ }^{1,2}$ \\ ${ }^{1}$ Department of Cataract, Shenzhen Eye Hospital, Shenzhen Eye Institute, Shenzhen Eye Hospital Affiliated to Jinan University, Shenzhen, China; \\ ${ }^{2}$ School of Optometry, Shenzhen University, Shenzhen, China; ${ }^{3}$ Department of Ophthalmology, Shenzhen People's Hospital, Second Clinical \\ Medical College, Jinan University, First Affiliated Hospital, Southern University of Science and Technology, Shenzhen, China \\ Contributions: (I) Conception and design: K Zeng; (II) Administrative support: K Zeng; (III) Provision of study materials or patients: Q Li; (IV) \\ Collection and assembly of data: W Xi; (V) Data analysis and interpretation: Y Qiao; (VI) Manuscript writing: All authors; (VII) Final approval of \\ manuscript: All authors. \\ Correspondence to: Kun Zeng. Department of Cataract, Shenzhen Eye Hospital, Shenzhen Eye Institute, Shenzhen Eye Hospital Affiliated to Jinan \\ University, Shenzhen, China; School of Optometry, Shenzhen University, Shenzhen 518040, China. Email: zengkun2063@163.com.
}

Backgrounda Improving patient comfort can provide patients with a better experience during surgery and
reflect the high-quality of hospital medical services. This study conducted a systematic review and meta-
analysis of several recent academic reports on improving patient comfort in cataract surgery to provide a
guide for clinical diagnosis and treatment. Methods: PubMed, Embase, and Web of Science were searched for reports on measures to improve the comfort of cataract patients. The retrieved reports were for randomized controlled studies published after January 2000. They were selected by two researchers and evaluated using the Jadad scale. The reports were then grouped according to the interventions used in the studies. Stata 16.0 software (StataCorp, TX, USA) was used to analyze the improvement noted with each intervention.

Results: Nineteen reports were included in this review, covering a total of 3,378 patients with cataract surgery. Results showed that the implementation of high-quality nursing techniques could reduce postoperative pain [standard mean difference $(\mathrm{SMD})=-1.19 ; 95 \%$ confidence interval $(\mathrm{CI}):-1.96$ to -0.43 ; $\mathrm{P}=0.002]$, the use of anxiolytic drugs (melatonin) could reduce postoperative anxiety in cataract patients (SMD $=-0.55 ; 95 \% \mathrm{CI}:-0.95$ to $-0.15 ; \mathrm{P}=0.007)$, and there was no significant difference in the topical anesthetic drugs used to improve patient comfort [odds ratio (OR) $=0.66$; 95\% CI: 0.31 to $1.40 ; \mathrm{P}=0.276$ ].

Discussion: During the perioperative period of cataract surgery, high-quality nursing techniques (preoperative video and audio education, limb massage or back massage, listening to soothing music) can reduce pain and anxiety. Anti-anxiety agents and preoperative sedatives can alleviate anxiety and improve comfort, but they are suitable for patients with high anxiety. What kind of surface anesthetic drugs are used in operation has no obvious help to improve comfort.

Keywords: Cataract; cataract surgery; pain; comfort; meta-analysis

Submitted Sep 22, 2021. Accepted for publication Nov 09, 2021.

doi: 10.21037/apm-21-2945

View this article at: https://dx.doi.org/10.21037/apm-21-2945

\section{Introduction}

A cataract is the degenerative build-up of lens proteins caused by aging, genetics, radiation, and abnormal nutrient metabolism. It decreases the patient's visual acuity and may eventually lead to blindness (1). Cataracts are more common in people over the age of 50 years and account for about $46 \%$ of cases of blindness worldwide (2). Surgery is the main treatment for cataracts, and visual acuity can be restored by replacing the cloudy lens (3). Surgical techniques now include precisely adjusted refractive 
Table 1 Search strategy: combination of keywords

\begin{tabular}{ll}
\hline Serial number & Keyword string \\
\hline 1 & "cataract surgery", "comfort" \\
2 & "cataract surgery", "pain" \\
3 & "cataract surgery", "anxiety" \\
4 & "cataract surgery", "satisfaction" \\
5 & "preoperative", "cataract surgery" \\
6 & "before surgery", "cataract surgery" \\
7 & "sedation", "before", "cataract surgery" \\
8 & "nursing", "cataract surgery" \\
9 & "music", "cataract surgery" \\
10 & "cataract surgery", "anesthesia" \\
\hline
\end{tabular}

surgery (4). Cataract patients have varying degrees of fear before operation, they are worried about unsuccessful operation, postoperative bleeding and infection complications, preoperative education should be done according to patients of different ages and different characteristics, so as to obtain the trust of patients and relieve their anxiety (5). Measures should be taken to improve patient comfort throughout surgery can provide patients with a better experience too. In the clinical setting, there are various measures that can improve patient comfort. A study performed by Shi et al. (6) had revealed that patients experienced pain and anxiety before surgery, but the study focused on comparing the pain between the first eye surgery and the second, rather than proposing nursing measures. In this study, we conducted a systematic review and meta-analysis of reports on the measures in recent years that may serve to guide clinical work and improve patient comfort.

We present the following article in accordance with the PRISMA reporting checklist (available at https://dx.doi. org/10.21037/apm-21-2945).

\section{Methods}

\section{Search strategy}

PubMed, Embase, and Web of Science were chosen as the primary query databases, although reports that met the criteria were also chosen from other sources (such as Google Scholar and hard copy media). Search filters were set for English-language studies published after the year
2000, and the keywords shown in Table 1 were used as the query parameters.

\section{Reports inclusion criteria}

\section{Study participants}

Participants were all patients with cataracts who underwent either monocular or binocular surgery (phacoemulsification, extracapsular cataract extraction, and intraocular lens implantation).

\section{Intervention methods}

Participants were divided into two randomized groups: the experimental group and the control group. The intervention method in the experimental group was to provide a nursing skill or drug that could improve peri- and postoperative comfort, regardless of the type of surgery, operation time, and the effects of surgery itself on patient comfort. The intervention method was only applied in the pre- or perioperative stages, without consideration of postoperative factors.

\section{Outcome indicators}

Primary outcome indicators included degree of anxiety, degree of pain, and patient satisfaction, one of which had to be assessed in the selected reports. Secondary indicators were postoperative blood pressure and visual acuity. To unify the data indicators, the degree of pain was reported using the visual analogue scale (VAS).

\section{Report exclusion criteria}

The exclusion criteria for studies were the following: (I) studies with dogs or other animals as intervention subjects; (II) nonrandomized controlled studies; (III) measures taken to improve comfort after surgery; and (IV) studies with obvious data errors or inaccuracies.

\section{Report selection and data extraction}

Two researchers independently completed an initial search, and studies were selected for inclusion according to the eligibility criteria. After the researchers had read the title, abstract, and full text, any repeated studies were filtered out, as were studies that did not meet the inclusion criteria. Both researchers independently completed the data extraction and cross-checked their work. The data extracted from the reports included the basic characteristics of the study, the 
basic characteristics of the study participants, the grouping and intervention methods, and the outcome data.

\section{Risk of bias and quality assessment}

The Jadad scale was used to evaluate the randomization method, blinding method, and data on withdrawals from the randomized controlled trial (RCT). The score for each aspect was $0-2$ points, with a total of 5 points. A score $\geq 3$ was considered a high-quality study.

\section{Statistical analysis}

\section{Tools}

This study used Stata 16.0 (StataCorp, TX, USA) as its primary analytical tool.

\section{Combined effects}

The VAS score was considered a continuous indicator, and the standard mean difference (SMD) and 95\% confidence interval (CI) were used to calculate the overall effect size. Satisfaction was a binary outcome, and the odds ratio (OR) and $95 \%$ CI were used to calculate the overall effect size. A $\mathrm{P}$ value $<0.05$ indicated statistically significant difference in effects, and a forest plot was used to present the results.

\section{Statistical heterogeneity}

Statistical heterogeneity was evaluated using Cochran $\mathrm{Q}$ and $\mathrm{I}^{2}$ tests. $\mathrm{I}^{2}>50 \%$ or $\mathrm{P}<0.1$ indicated statistically significant heterogeneity.

\section{Statistical methods and effect models}

The Mantel-Haenszel method was used to calculate the OR, while the inverse variance method was used to calculate the SMD. If heterogeneity existed between reports, a random effects model was used; otherwise, a fixed-effects model was used.

\section{Heterogeneity investigation}

If the analysis revealed statistical heterogeneity between studies, the heterogeneity was assessed by excluding the reports one by one. When the source of heterogeneity could not be determined, only a descriptive analysis was performed.

\section{Handling of missing data}

If data regarding the outcome indicators were not given in the article, the authors were contacted to supplement the existing data. If the authors could not be contacted or had lost the data, the article was only described and not included in the analysis.

\section{Grouping for analysis}

This review assesses measures taken to improve the comfort of cataract patients. Given the large scope for heterogeneity between the different measures, the reports were grouped for synthesis according to the intervention type as follows: nursing method, preoperative sedation, preoperative anxiolytic drugs, anesthetic drugs, and other methods. The number of reports included in each synthesis group was $\geq 2$. If the intervention method in a report could not be grouped with other reported methods, only a descriptive analysis was performed.

\section{Sensitivity analysis}

Sensitivity analyses were carried out using the sensitivity analysis tool provided by Stata 16.0 (StataCorp).

\section{Publication bias analysis}

Publication bias analysis was performed using a funnel plot.

\section{Results}

\section{Literature screening process and results}

The document retrieval flow chart is shown in Figure 1. Of the 404 reports initially retrieved, 19 were selected after screening, giving a total of 3,378 cases of cataract surgery.

\section{Basic characteristics and quality evaluation of reports}

The basic characteristics and Jadad evaluation scores of the included reports are shown in Table 2.

\section{Meta-analysis results}

Effect of nursing methods on improving postoperative comfort of patients

A total of 8 reports adopted preoperative nursing interventions (as shown in Table 3). However, considering the different scales used for measuring anxiety in the reports, a meta-analysis could not be performed. Only 4 reports $(7-9,13)$ indicating VAS scores were included in the meta-analysis. Heterogeneity $\left(\mathrm{I}^{2}=93.5 \%\right.$; $\left.<<0.00001\right)$ was observed. The random effects model was used to obtain the combined statistic (SMD $=-1.19 ; 95 \%$ CI: -1.96 to -0.43 ). 


\section{Identification of studies via databases and registers}
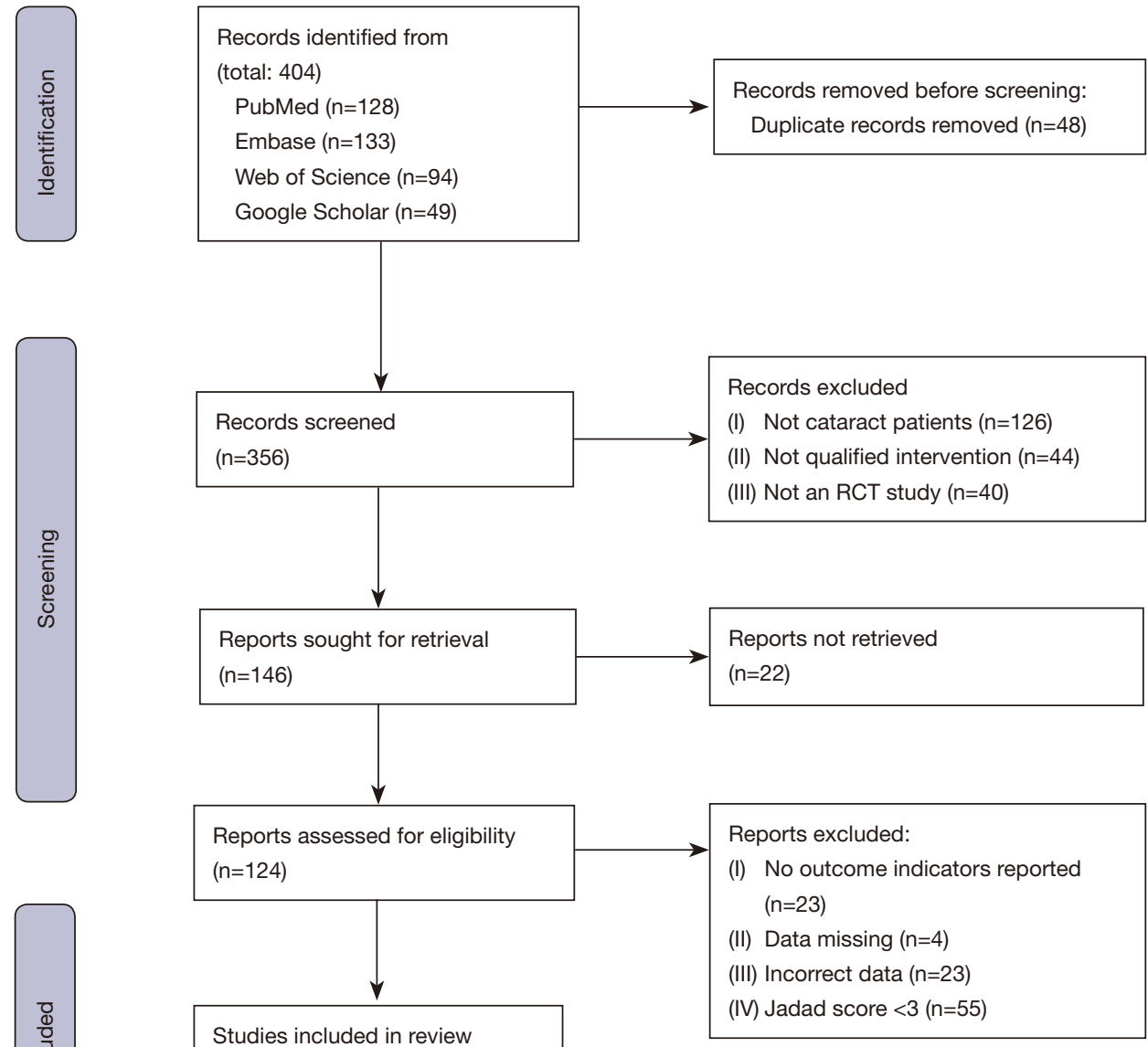

$(\mathrm{n}=19)$

Reports of included studies

$(n=19)$

Figure 1 Flowchart of literature search and selection. RCT, randomized controlled trial.

This result indicates that improving nursing methods could reduce postoperative pain $(\mathrm{Z}=-3.059 ; \mathrm{P}=0.002)$ The results are shown in Figure 2.

\section{Effect of preoperative sedation on improving patient comfort}

A total of 3 reports suggested that preoperative sedatives could reduce both anxiety and the degree of pain experienced by patients (14-16). However, meta-analysis could not be performed as the reporting methods of the indicators used in each report could not be grouped. The results are shown in Table 4.
Effect of anxiolytic drugs on improving patient comfort A total of 2 reports (as shown in Table 5) suggested that the use of preoperative oral melatonin could reduce patient anxiety. A meta-analysis was performed for the outcome indicators of verbal anxiety scores, and there was no heterogeneity in the articles $\left(\mathrm{I}^{2}=0.0 \% ; \mathrm{P}=0.564\right)$. Using the fixed effects model, the pooled statistic value was SMD $=-0.55$ ( $95 \%$ CI: -0.95 to -0.15 ), with statistical significance $(\mathrm{Z}=-2.675 ; \mathrm{P}=0.007)$. These results indicate that the use of anxiolytic drugs (melatonin) could reduce the degree of postoperative anxiety in cataract patients. The results are shown in Figure 3. 
Table 2 Basic characteristics and Jadad score of included reports



\section{Effect of topical anesthetic drugs on improving patient} comfort

A total of 3 reports (as shown in Table 6) compared lidocaine to other anesthetic drugs used in surgery. No heterogeneity was detected in the reports $\left(\mathrm{I}^{2}=0.0 \% ; \mathrm{P}=0.368\right)$. The fixed effects model was used to analyze patient satisfaction outcome indicators, and the pooled statistics value were $\mathrm{OR}$ $=0.66$ (95\% CI: 0.31 to 1.40 ), and no statistical significance was found $(\mathrm{Z}=-1.089 ; \mathrm{P}=0.276)$. These results indicate that there was no significant difference in patient satisfaction concerning the topical anesthetic drug used. The results are shown in Figure 4.

\section{Effect of other measures on improving patient comfort} Three reports (as shown in Table 7) suggested that other intervention methods may have an effect on patient comfort, but as only 1 such intervention measure was reported, it could not be included in the meta-analysis. 
Table 3 Effect of nursing methods on improving comfort

\begin{tabular}{|c|c|c|c|c|}
\hline Literature & $\begin{array}{l}\text { Number of participants } \\
\text { grouped }(E / C)\end{array}$ & Group E intervention methods & $\begin{array}{c}\text { Group } \mathrm{C} \text { intervention } \\
\text { methods }\end{array}$ & Outcome measures \\
\hline Choi S et al. (7) & $23 / 29$ & Korean traditional music & None & VAS score; blood pressure; pulse \\
\hline Pager CK (8) & $73 / 68$ & Preoperative video education & None & VAS score \\
\hline Çavdar AU et al. (9) & $70 / 70$ & Preoperative massage & None & VAS score \\
\hline $\begin{array}{l}\text { Farmahini Farahani M } \\
\text { et al. (11) }\end{array}$ & $30 / 30$ & Preoperative limb massage & None & $\begin{array}{l}\text { Anxiety score, heart rate, blood } \\
\text { pressure, respiration }\end{array}$ \\
\hline Kekecs Z et al. (12) & $42 / 42$ & $\begin{array}{c}\text { Audio (including music and } \\
\text { education) }\end{array}$ & None & Heart rate, sleep, cooperativeness \\
\hline
\end{tabular}

E, experimental group; C, control group; VAS, visual analogue scale.

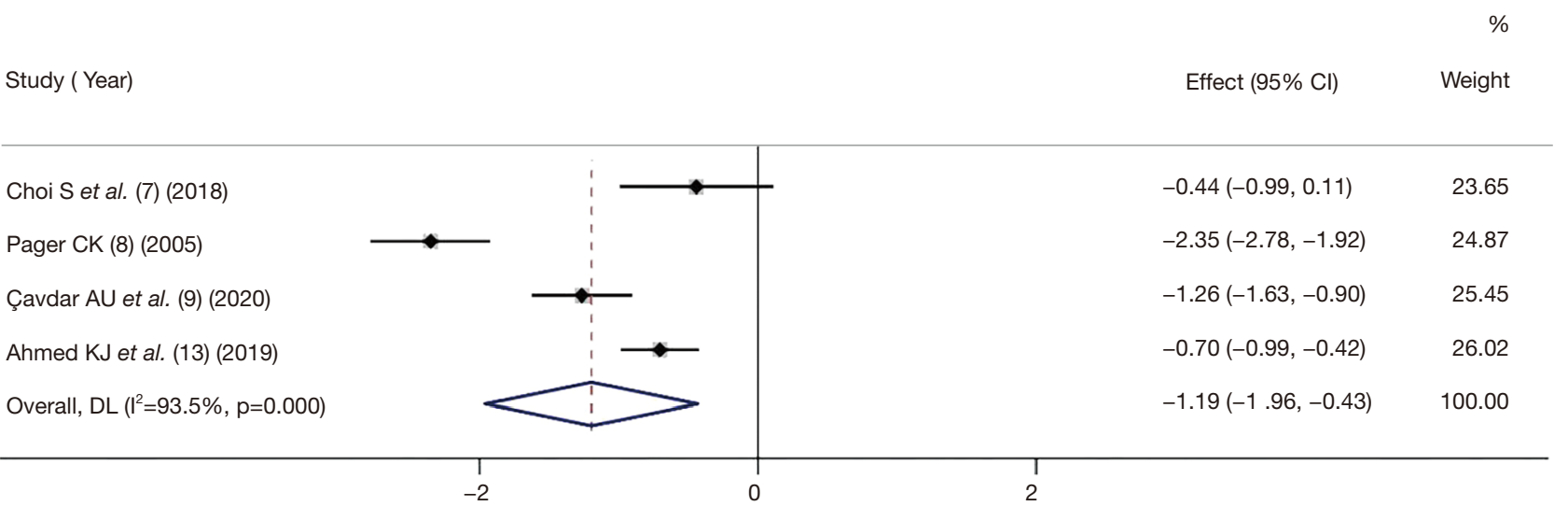

NOTE: Weights are from random-effects model

Figure 2 Combined effects analysis of nursing methods for improving patient comfort $(7-9,13)$.

Table 4 Effect of preoperative sedation on improved comfort

\begin{tabular}{lclll}
\hline Literature & $\begin{array}{c}\text { Number of participants } \\
\text { grouped }(E / C)\end{array}$ & Group E intervention methods & $\begin{array}{l}\text { Group C intervention } \\
\text { methods }\end{array}$ & Outcome measures \\
\hline Chen M et al. (14) & $83 / 73$ & Preoperative oral midazolam & Oral diazepam & Anxiety ratio \\
Habib NE et al. (15) & $50 / 50$ & $\begin{array}{l}\text { Preoperative intravenous } \\
\text { midazolam }\end{array}$ & None & VAS score, anxiety \\
score & Preoperative intravenous \\
Erdurmus $M$ et al. (16) & $22 / 22$ & Intravenous normal saline & Proportion of pain \\
& & severity &
\end{tabular}

E, experimental group; C, control group; VAS, visual analogue scale. 
Table 5 Effects of anxiolytic medications on improving comfort

\begin{tabular}{|c|c|c|c|c|}
\hline Ismail SA et al. (18) & $20 / 20$ & Preoperative oral melatonin & Placebo & Verbal anxiety scores \\
\hline
\end{tabular}

E, experimental group; C, control group.

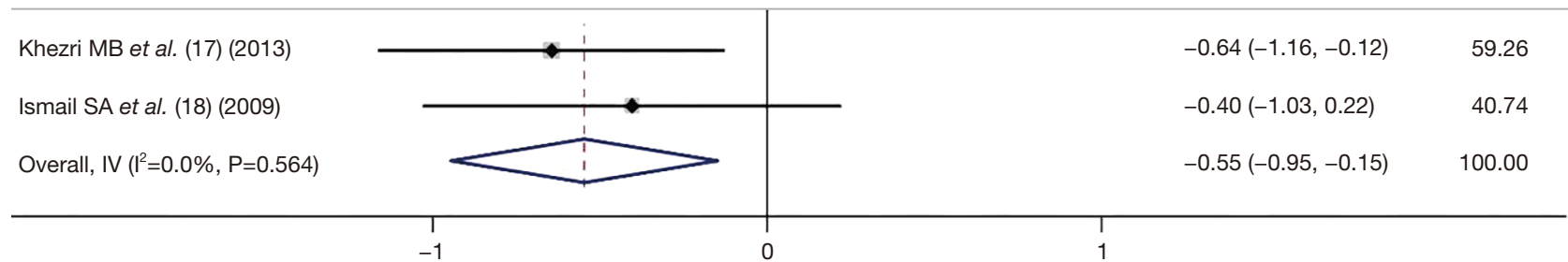

Figure 3 Combined effects analysis of anxiolytic drugs for improving patient comfort $(17,18)$.

Table 6 Effects of topical anesthetics on improved comfort

\begin{tabular}{lcccc}
\hline Literature & $\begin{array}{c}\text { Number of participants } \\
\text { grouped (E/C) }\end{array}$ & $\begin{array}{c}\text { Group E intervention } \\
\text { methods }\end{array}$ & $\begin{array}{c}\text { Group C intervention } \\
\text { methods }\end{array}$ & Outcome measures \\
\hline Fernández SA et al. (19) & $126 / 120$ & $0.75 \%$ levobupivacaine & $2 \%$ lidocaine & $\begin{array}{c}\text { Pain proportion and } \\
\text { satisfaction rate }\end{array}$ \\
Ugur B et al. (20) & $32 / 32$ & $1 \%$ ropivacaine & $2 \%$ lidocaine & Satisfaction rate \\
Raman SV et al. (21) & $34 / 31$ & $4 \%$ articaine & $2 \%$ lidocaine & Satisfaction rate \\
\hline
\end{tabular}

E, experimental group; C, control group.

\begin{tabular}{|c|c|c|}
\hline \multirow[b]{2}{*}{ Study ( Year) } & & $\%$ \\
\hline & & leight \\
\hline Fernández SA et al. (19) (2009) & 33) & 5767 \\
\hline Ugur B et al. (20) (2007) & & 1627 \\
\hline Raman SV et al. (21) (2008) & .89) & 26.05 \\
\hline Overall, $\mathrm{MH}\left(\mathrm{I}^{2}=0.0 \%, \mathrm{P}=0.368\right)$ & & 00.00 \\
\hline
\end{tabular}

NOTE: Weights are from Mantel-Haenszel model

Figure 4 Combined effects analysis of topical anesthetic drugs for improving patient comfort (19-21). 
Table 7 Effects of other measures on improving comfort

\begin{tabular}{|c|c|c|c|c|}
\hline Literature & $\begin{array}{l}\text { Number of participants } \\
\text { grouped }(E / C)\end{array}$ & Group E intervention methods & Group C intervention methods & Outcome measures \\
\hline Ulaş F et al. (22) & $40 / 40$ & $\begin{array}{l}\text { Preoperative reduction of } \\
\text { intraocular pressure }\end{array}$ & None & Pain VAS score \\
\hline Price MO et al. (23) & $25 / 25$ & $\begin{array}{c}\text { Preoperative } 0.4 \% \text { ketorolac } \\
\text { eye drops }\end{array}$ & Saline & Pain perception \\
\hline Modi SS et al. (25) & $817 / 819$ & $\begin{array}{l}\text { Postoperative once-daily } \\
\text { nepafenac ophthalmic } \\
\text { suspension } 0.3 \%\end{array}$ & $\begin{array}{c}3 \text { times daily nepafenac } \\
\text { ophthalmic suspension } 0.1 \%\end{array}$ & Pain perception \\
\hline
\end{tabular}

E, experimental group; C, control group; VAS, visual analogues scale.

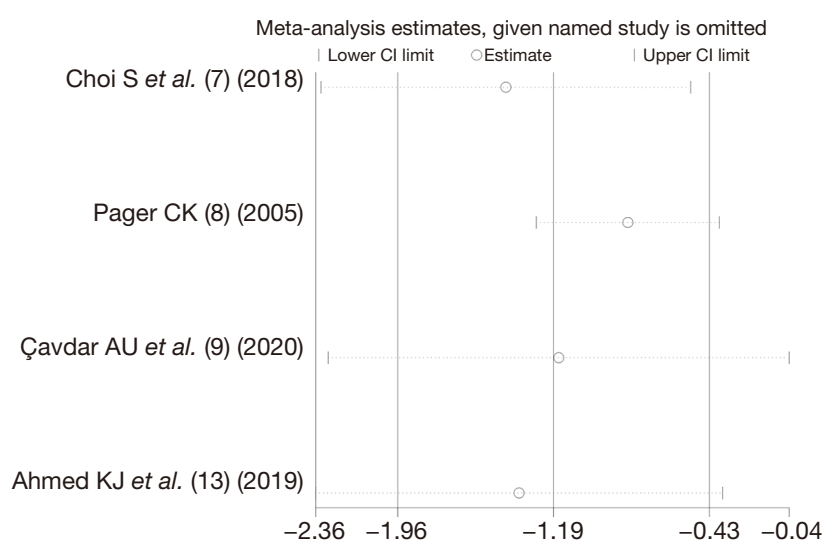

Figure 5 Sensitivity analysis plots for efficacy measures $(7-9,13)$.

\section{Heterogeneity investigation and sensitivity analysis}

On the analysis for effect of nursing interventions, the heterogeneity mainly came from the difference between kinds of nursing methods. Sensitivity analysis of the efficacy of nursing methods used to improve patient comfort showed that the distribution of the 4 reports was uniform and that stability was good. The results are shown in Figure 5.

\section{Publication bias analysis}

As the number of reports included in this review was small for all indicators, no publication bias analysis was performed.

\section{Discussion}

A total of 19 reports on improving the pre- and perioperative comfort (and thus postoperative comfort) of cataract patients were retrieved from several databases for this meta-analysis. The interventions discussed in the reports included nursing techniques, preoperative sedative use, preoperative anxiolytic use, topical anesthetic use, and other measures conducive to improving comfort. The reports found that high-quality nursing techniques, such as allowing patients to listen to soothing music before surgery or using massage to relax them, can effectively improve patient comfort, reduce preoperative anxiety, enhance the effect of surgery, and reduce postoperative pain. Preoperative multimedia educational resources are also worthy of note. Audio or video presentations can be used to give patients relevant knowledge about cataracts and inform them of perioperative precautions, good postoperative habits, and other issues. Having this knowledge can reduce the patient's fear of surgery, improve their awareness of cooperation, and increase their confidence in surgery, all of which in turn can improve peri- and postoperative comfort. Sedation, such as oral (or intravenous) midazolam, can relieve postoperative pain and anxiety (14-16), but the indicators found in the selected reports could not be synthesized, so a meta-analysis of this intervention was not performed. The use of anxiolytic drugs can reduce the anxiety of cataract patients during surgery and is more suitable for patients with anxiety symptoms. There was little difference in comfort between the drugs that were used as topical anesthetics (levobupivacaine, lidocaine, articaine). Studies using preoperative intraocular pressure reduction (22) or the preoperative application of $0.4 \%$ ketorolac eye drops (23) demonstrated that these measures can reduce subjective pain in patients, but the number of such studies was too small to be included in the meta- 
analysis. The results of this review showed that there was no significant difference in the improvement of comfort between topical and periocular anesthesia. Postoperative care is very important for the overall success of surgery. Nurses should carefully observe the surgical eye dressing, in case of bleeding, the dressing should be replaced in time to prevent infection; Patients should be educated to lie flat after operation, avoid strenuous exercise and prevent bleeding caused by increased intraocular pressure. A study (25) suggested the postoperative use of once-daily nepafenac ophthalmic suspension to prevent and treat ocular pain and inflammation after cataract surgery, the results was good.

The 16 reports included in this study were all RCT with a Jadad score of more than 3 points. However, our metaanalysis still had a few limitations. First, the term "comfort" could not be precisely defined. As no scales directly measuring comfort were found, pain, anxiety, and patient satisfaction were included as an ad hoc definition of comfort for this review. Second, the indicator scales employed in the reports were not uniform. For example, when measuring anxiety, the reports used different scales and scoring criteria, which were difficult to summarize for meta-analysis. Third, errors in measurement might have been present. As comfort is a subjective feeling and highly susceptible to interference from other factors, it is highly likely that errors will occur when subjective measures (e.g., visual pain scales, visual anxiety scales) are used. Fourth, this review did not take into account the type of surgery. However, studies have shown that the type, effect, and duration of surgery can affect patients' postoperative comfort (26). Finally, there were too few relevant reports in some areas. For example, lowering intraocular pressure may improve comfort, but only 1 report included in this review mentioned this method. Therefore, more high-quality RCT studies should be included to further explore measures to improve the comfort of patients undergoing cataract surgery.

\section{Conclusions}

During the perioperative period of cataract surgery, highquality nursing techniques (preoperative video and audio education, limb massage or back massage, listening to soothing music) can reduce pain and anxiety. Anti-anxiety agents and preoperative sedatives can alleviate anxiety and improve comfort, but they are suitable for patients with high anxiety. What kind of surface anesthetic drugs are used in operation has no obvious help to improve comfort.
However, more high-quality randomized controlled studies on this topic are needed to provide stronger evidence.

\section{Acknowledgments}

Funding: This work was supported by the San Ming Project of Medicine in Shenzhen (No. SZSM201812091).

\section{Footnote}

Reporting Checklist: The authors have completed the PRISMA reporting checklist. Available at https://dx.doi. org/10.21037/apm-21-2945

Conflicts of Interest: All authors have completed the ICMJE uniform disclosure form (available at https://dx.doi. org/10.21037/apm-21-2945). The authors have no conflicts of interest to declare.

Ethical Statement: The authors are accountable for all aspects of the work in ensuring that questions related to the accuracy or integrity of any part of the work are appropriately investigated and resolved.

Open Access Statement: This is an Open Access article distributed in accordance with the Creative Commons Attribution-NonCommercial-NoDerivs 4.0 International License (CC BY-NC-ND 4.0), which permits the noncommercial replication and distribution of the article with the strict proviso that no changes or edits are made and the original work is properly cited (including links to both the formal publication through the relevant DOI and the license). See: https://creativecommons.org/licenses/by-nc-nd/4.0/.

\section{References}

1. Chan WH, Biswas S, Ashworth JL, et al. Congenital and infantile cataract: aetiology and management. Eur J Pediatr 2012;171:625-30.

2. Schmitt C, Hockwin O. The mechanisms of cataract formation. J Inherit Metab Dis 1990;13:501-8.

3. Davis G. The Evolution of Cataract Surgery. Mo Med 2016;113:58-62.

4. Sharma B, Abell RG, Arora T, et al. Techniques of anterior capsulotomy in cataract surgery. Indian J Ophthalmol 2019;67:450-60.

5. Li X. Application of evidence-based nursing in patients after cataract surgery and its impacts on visual acuity 
recovery and psychological status. Am J Transl Res 2021;13:9784-9.

6. Shi C, Yuan J, Zee B. Pain Perception of the First Eye versus the Second Eye during Phacoemulsification under Local Anesthesia for Patients Going through Cataract Surgery: A Systematic Review and Meta-Analysis. J Ophthalmol 2019;2019:4106893.

7. Choi S, Park SG, Bellan L, et al. Crossover clinical trial of pain relief in cataract surgery. Int Ophthalmol 2018;38:1027-33.

8. Pager CK. Randomised controlled trial of preoperative information to improve satisfaction with cataract surgery. Br J Ophthalmol 2005;89:10-3.

9. Çavdar AU, Yilmaz E, Baydur H. The Effect of Hand Massage Before Cataract Surgery on Patient Anxiety and Comfort: A Randomized Controlled Study. J Perianesth Nurs 2020;35:54-9.

10. Mohammadpourhodki R, Sargolzaei MS, Basirinezhad MH. Evaluating the effect of massage based on slow stroke back massage on the anxiety of candidates for cataract surgery. Rom J Ophthalmol 2019;63:146-52.

11. Farmahini Farahani M, Noruzi Zamenjani M, Nasiri M, et al. Effects of Extremity Massage on Preoperative Anxiety: A Three-Arm Randomized Controlled Clinical Trial on Phacoemulsification Candidates. J Perianesth Nurs 2020;35:277-82.

12. Kekecs Z, Jakubovits E, Varga K, et al. Effects of patient education and therapeutic suggestions on cataract surgery patients: a randomized controlled clinical trial. Patient Educ Couns 2014;94:116-22.

13. Ahmed KJ, Pilling JD, Ahmed K, et al. Effect of a patientinformation video on the preoperative anxiety levels of cataract surgery patients. J Cataract Refract Surg 2019;45:475-9.

14. Chen M, Hill GM, Patrianakos TD, et al. Oral diazepam versus intravenous midazolam for conscious sedation during cataract surgery performed using topical anesthesia. J Cataract Refract Surg 2015;41:415-21.

15. Habib NE, Mandour NM, Balmer HG. Effect of midazolam on anxiety level and pain perception in cataract surgery with topical anesthesia. J Cataract Refract Surg 2004;30:437-43.

16. Erdurmus M, Aydin B, Usta B, et al. Patient comfort and surgeon satisfaction during cataract surgery using topical anesthesia with or without dexmedetomidine sedation. Eur J Ophthalmol 2008;18:361-7.
17. Khezri MB, Merate $H$. The effects of melatonin on anxiety and pain scores of patients, intraocular pressure, and operating conditions during cataract surgery under topical anesthesia. Indian J Ophthalmol 2013;61:319-24.

18. Ismail SA, Mowafi HA. Melatonin provides anxiolysis, enhances analgesia, decreases intraocular pressure, and promotes better operating conditions during cataract surgery under topical anesthesia. Anesth Analg 2009;108:1146-51.

19. Fernández SA, Dios E, Diz JC. Comparative study of topical anaesthesia with lidocaine $2 \%$ vs levobupivacaine 0.75\% in cataract surgery. Br J Anaesth 2009;102:216-20.

20. Ugur B, Dundar SO, Ogurlu M, et al. Ropivacaine versus lidocaine for deep-topical, nerve-block anaesthesia in cataract surgery: a double-blind randomized clinical trial. Clin Exp Ophthalmol 2007;35:148-51.

21. Raman SV, Barry JS, Murjaneh S, et al. Comparison of $4 \%$ articaine and $0.5 \%$ levobupivacaine $/ 2 \%$ lidocaine mixture for sub-Tenon's anaesthesia in phacoemulsification cataract surgery: a randomised controlled trial. $\mathrm{Br} \mathrm{J}$ Ophthalmol 2008;92:496-9.

22. Ulaş F, Balbaba M, Çelebi S. Effect of prophylactic intraocular pressure-lowering medication on pain during cataract surgery. J Ocul Pharmacol Ther 2013;29:658-62.

23. Price MO, Price FW. Efficacy of topical ketorolac tromethamine $0.4 \%$ for control of pain or discomfort associated with cataract surgery. Curr Med Res Opin 2004;20:2015-9.

24. Sauder G, Jonas JB. Topical versus peribulbar anaesthesia for cataract surgery. Acta Ophthalmol Scand 2003;81:596-9.

25. Modi SS, Lehmann RP, Walters TR, et al. Once-daily nepafenac ophthalmic suspension $0.3 \%$ to prevent and treat ocular inflammation and pain after cataract surgery: phase 3 study. J Cataract Refract Surg 2014;40:203-11.

26. Liu P, Zhang S, Geng Z, et al. Factors affecting pain in patients undergoing bilateral cataract surgery. Int Ophthalmol 2020;40:297-303.

(English Language Editors: L. Roberts and J. Gray)

Cite this article as: Zeng K, Li Q, Xi W, Qiao Y. Measures to improve the comfort of cataract surgery patients: a systematic review and meta-analysis. Ann Palliat Med 2021;10(11):1184911858. doi: 10.21037/apm-21-2945 